\title{
Motive and Perception as Distinguishing Factors of the use of Analog Camera in the Digital Area
}

\author{
Dadan Iskandar, Suraya Mansur, Rajab Ritonga, Novita Damayanti
}

Department of Communication Science, Universitas Mercu Buana, Jakarta, Indonesia

\begin{abstract}
This research is aimed to identify the motives of analog camera users in using the analog camera in the midst of current digital era. It is also conducted to understand the society's perception and opinion on the existence of analog camera in current digital era. The theory employed in this research is "Uses and Gratification" by Elihu Katz and Jay G. Blumler. This theory corroborates that generally the society uses the media for specific motives. Perception is predicated on three things; selection, organization, and interpretation. Selection consists of sensation and attention; meanwhile organization is heavily linked to interpretation which is defined as "attaching a stimulus with other stimuli to derive the whole meaning". This research uses a positivist or classical paradigm with a quantitative approach and a descriptive research form. The data collected for this research was taken from a survey with dozens of questions done to 117 people, consisting of analog camera users and the cyber society. The data analysis used here is discriminant analysis. The result of the research shows that there is a motive of using the analog camera predicated by a desire to experience using analog camera and a desire to gain prestige; the accuracy of using this discriminant model is 57,1\%. Meanwhile from the perception argument, the use of analog camera is predicated by "a perception to have unique analog camera images", "a perception to look skilful in photography" and "a perception to cultivate the skills in photography", the accuracy of this prediction achieves $47,1 \%$.
\end{abstract}

Keywords_analog camera, digital culture, discriminant analysis, perspective.

\section{INTRODUCTION}

As we move into the digital era, the rise of technology which eases the human life has subsequently created significant change in the social system. Rogers [1] describes that technology is a design of instrumental activity, aimed to reduce the uncertainty resulted from the consequence of causal effect as well to achieve the desired goal. Technology generally can be a hardware and software.

Digitalization, for Rogers (Rogers, 2001), is a product of innovation, meanwhile innovation is described as an idea, thought, or concept deliberately accepted as a new thing for the society or other units receiving it. In other words, digitalization is one of the products of diffusion of innovations model. Everett M. Rogers defines diffusion as a process which an innovation is deliberately communicated through a channel over a period of time within the members of a social system. Diffusion is a particular form of communication, highly related to spreading new ideas. Within the message, there is a novelty which becomes an exclusive characteristic for diffusion which carries uncertainty. The condition of social and technological change within the society has created needs which subsequently substitute the old methods with the new ones. [2][3]

Digitalization has also penetrated into the world of camera. Camera is an instrument to capture moments or events, as well as a medium functioned to convey a message through an image. Today, the mirrorless camera is probably the newest innovation from the previously existing DSLR technology. Mirrorless is essentially a DSLR camera, removed in its mirror box. Without the mirror box, created to deflect the light from the lens onto the optical viewfinder, the size of mirrorless is significantly reduced compared to DSLR, but it still maintains its image recording quality further with its lens can be easily substituted.

(https://tekno.kompas.com/read/2016/09/13/10470087/apa. itu.kamera.mirrorless.bedanya.dengan.dslr. Accessed in March 27, 2018)

Digital camera supports taking as many pictures according to the size of camera storage, it also enables us to easily delete some pictures taken, either mistaken or better discarded pictures. Different to analog camera, the 
latter is different in its process of capturing the image, storing with relatively smaller size, but also it is incapable of instantly deleting the taken pictures and it requires longer time to print its pictures compared to mirrorless camera.

This phenomenon can be observed from the high number of visitors of Lowlight Bazaar, an analog photography bazaar. That bazaar has been held twice since 2010. Renaldy Fernando, the founder of Jellyplayground, an analog camera enthusiasts forum, states that the event in 2017 was the eleventh occasion and it managed to attract 1700 visitors. The growth of analog camera photography can also be observed through the search on Carousell phone marketplace. The president and Co-founder of Carousell, Marcus Tan, states that there are 38000 listings in photography category and analog camera steps us to be the most searched item. (https://www.antaranews.com/berita/658414/kameraanalog-kembali-dicari-kenapa. Accessed on March 27, $\underline{2018)}$

Besides, many analog camera enthusiast communities have emerged. For instance, Jellyplayground, Komunitas Kamera Analog Jogja, Indonesian Analog Photography Enthusiast Community (IdFilm), Lomonesia Indonesia, and many others. Those community members are spread out in different areas in Indonesia. They manage to share knowledge and experience in using and studying the analog camera. They also find shared objects to their photo, upload it on their own community page on social media, as well as publish it to the vast society or any other analog camera enthusiasts outside their own community.

Based on Kompas Tekno observation on Wednesday, August 2, 2017, it is estimated that no less than 150,000 pictures with hashtag \#indo35mm are spread out on Instagram. What does the hashtag $\# 35 \mathrm{~mm}$ signify? $35 \mathrm{~mm}$ refers to the most common type used in analog camera. The colouring produced in the analog camera pictures is essentially quite similar to the presets existed in some editing apps such as VSCO, SnapSeed, etc. Mainstream picture effects from analog camera such as flare or burn are also provided in the editing apps of digital photo. (https://tekno.kompas.com/read/2017/08/02/14282837/kam era-roll-film-ngetren-lagi-foto-35mm-ramai-di- instagramtanah-air. Accessed on March 27, 2018)

This someway indicates that the analog camera does not necessarily collapse in the current digital era. The analog camera still attracts many enthusiasts. The society actively utilizes media in purpose of fulfilling their necessity. This means that the society uses media to gain gratification for their needs.
This phenomenon is thought-provoking to be researched and studied for what are the laymen and analog or digital camera photographers' perception and opinion on this matter, and what are their reasons in using analog camera as a medium of conveying message through an picture in this digital era. Having elaborated this background, the questions posed in this research are: "How far do perception and motive become distinguishing factors to the use of analog camera in the digital era?" The purpose of this research is as follows: (1) To know the motive of the analog camera users in reviving the use of analog camera in recent digital era; (2) To know the perception, opinion, and perspective of the cyber society on the existence of analog camera in today's digital era.

\section{LITERATURE REVIEW}

Everret M. Rogers explains that technological development is, in essence, in a line with establishment of communication, the diffusion of innovation. For Rogers, diffusion is a process at which an innovation is communicated to several channels within particular period. Diffusion is a specific form of communication, related to the spread of innovation as a new idea, on this matter, it is the development of analog to digital camera. Rogers also propounds 5 categories of adopters, they are: (1) Innovator (2) Early Adopters (3) Early Majority (4) Late Majority (5) Laggards. [3][1].

In this research, some individuals are known to keep using analog camera in this digital era. The society is actively using media to fulfil their needs. On this matter, the study focuses on the uses of media as to gain gratification for the need of individual.

Some researches using Uses and Gratification theory have been done many times, for instance a study on the spread of pictures through facebook [4], [5], news publishing in the old and new medias [6], using e-book [7], the use of weChat in China [8], study by e-learning [9], mobile communication [10], [11], [12], [13]. This theory, however, employs Uses and Gratification theory in the use of analog camera.

Katz et al. and Dennis McQuail describe the logic which predicates the Uses and Gratification research. [14]. Katz, Gurevitch, dan Haas see that the mass media is an instrument utilized by the individual to connect to the others. This need has actually been classified into 5 categories: (1) Cognitive Need (2) Affective Need (3) Integrative Personal Need (4) Integrative Social Need (5) Tension Release Need.

The gratification is built from hopes. In other sides, 
hope affects perception. Perception [15] [16] is an internal process which enables us to choose, organize, and interpret the stimuli given from our surroundings, and that process essentially affects us. Perception includes sensing through our possessed senses, attention, and interpretation. Sensation refers to the message carried to the brain through sight, hearing, touching, smelling, and tasting.

Perception consists of three activities: selection, organization, and interpretation. Selection actually covers sensation and attention, while organization is predicated on interpretation which can be defined as "attaching the stimulus with other stimuli to derive the whole meaning". These three perception stages (sensation, attention, and interpretation or selection, organization, and interpretation) cannot be strictly distinguished as to when one stage ends and the next stage starts. [17], [18], [19].

Analog camera is a type of camera with its capturing technique using celluloid film, at which the film has three basic elements, the optic, chemical, and mechanic element. Optic element consists of lens and its variety, meanwhile the chemical element is, in essence, the celluloid film. The mechanic element is the camera body and any other components in it. Analog camera is often called as "film camera" because of the use of film as its main storage compared to memory card in digital camera. (http://scdc.binus.ac.id/klifonara/2017/06/kelebihankamera-analog/. Accessed in March 27, 2018)

While camera advances in evolution, it actually gets smaller and lighter therefore enabling us to carry it more easily. Though the instrument has probably changed in size and shape, for hundreds of years, the principle of film camera in recording image is consistently the same, to capture the permanent image assisted by the chemical components reacting to the presence of the light. (https://tekno.kompas.com/read/2017/08/05/10465657/berk enalan-dengan-kamera-film-yang-kembali- digandrungi-diindonesia?page+all. Accessed in April 13, 2018)

Film format that is commonly used is film 135. It got popularized by a German camera factory, Leica, in the beginning of $20^{\text {th }}$ century because of its small size and therefore allowing a smaller size of camera which used it then. The type of camera which uses film 135 can also be distinguished into different categories, such as rangefinder, compact camera, SLR (single lens reflect), and polaroid camera.

The research on analog camera has been various, for instance in studying the quality, superiority, and the shortcomings of analog camera [20], image quality [21], product quality and brand image of analog camera [22], quality of lighting [23], and the produced picture precision
[24].

\section{RESEARCH METHOD}

This research employs descriptive quantitative research with survey method and positivist paradigm. The quantitative approach is deliberately chosen as the object of this research is a process or activity or the act of some people, here it is the photography community which uses analog camera as the instrument. This research is an attempt to analyse the opinion and perception of cyber society as the analog camera is revived in this digital era. The survey method also enables us to generalize the certain social phenomenon or variable to greater social phenomenon or social variable. (Bungin, 2005)

The population in this research is some people consisting of cyber society who use analog camera and those do not. The sample of this research consists of 2 parts, they are: (1) Member of analog camera community in Jakarta, Kelas Bina Pagi Analog, consisting of 20 people (2) Cyber society consisting of 97 people.

The sampling technique used here is nonprobability sampling, respectively the purposive sampling. The researcher therefore analysed from two sides respectively the analog camera user and the cyber society who observed the trend of analog camera usage in this digital era. Thus, there are 117 samples in total within this research. The collection data technique was done by giving the questionnaires to the respondents.

This research also employs Univariate analysis. Univariate analysis is an analysis on one variable. This type of analysis is deliberately selected for descriptive research. This research uses descriptive statistics. Descriptive statistics is employed as to describe an event, behaviour or any other particular objects (Bungin, 2005)

Besides, to purposefully know the difference of analog camera users, this research uses discriminant analysis technique, a statistical technique employed for dependent relation (a relation among variables at which responding and explanatory variables can be distinguished). This discriminant analysis is aimed to classify an individual or observation into mutually exclusive and exhaustive category based on several explanatory variables. [25] http://daps.bps.go.id/file_artikel/65/ANALISIS\%20DISKR IMINAN.pdf Accessed in December 31, 2019).

\section{RESULT AND DISCUSSION}

The respondents, 117 people in total, consist of 51 females and 66 males. Most are university students, respectively 62 
people with an average of age ranged from 16 to 25 years old. The rest are 48 people with an average of age ranged from 26 to 35 years, meanwhile only 7 people ranged from $36-45$ years old. The respondents are private employees with 52 people, 30 from university students, 12 people from both freelancers and unemployed, government officers with 11 people, 8 people from entrepreneurs, and 4 participants from photographers.

The vast majority of respondents $(86,32 \%)$ have photography as their hobby and merely 16 people who do not share the hobby. Those who have this hobby, $28 \%$ of them are analog camera users, $31 \%$ of them are digital camera users, and $27 \%$ are the phone camera users. Observing the frequency of doing the photography, many respondents $(53,85 \%)$ still allocate their time to do photography. Based on the camera type operated, those using phone camera are still the majority $(39,32 \%)$. Meanwhile, the least are the analog camera users $(28,21 \%)$.

\subsection{Motive}

A distinguishing analysis on analog camera users was done based on the respondents' answer to "motive and perception" variable, with the highest mean $(4,1$ and 4,0$)$ is on the motive of "a desire to experience analog camera" and "a desire of unique analog camera images" within the analog camera users; meanwhile, the mean is 3,8 on the digital camera users. However, on the phone camera users, the highest mean was scored on the motive of "a desire to remove boredom" $(3,28)$ and "a desire of unique analog camera images" $(3,27)$.

Only one variable has sig $>0,05$, which is "desire to remove boredom". The rest 8 variables present a difference in the use of different camera type. To test the similarity of varians, here it is used Box's $M$ test with a criterion of judgment: if significance level $(\alpha)>0,05$ therefore $H_{0}$ is approved; conversely, if significance level $(\alpha)<0,05$ consequently $\mathrm{H}_{\mathrm{o}}$ is rejected.

The examined hypotheses in this instance are:

$\mathrm{H}_{0}=$ Varians of two groups of identical or homogenous data

$\mathrm{H}_{1}=$ Varians of two groups of non-identical or heterogeneous data

The results of Box's $M$ test are the followings:
Table 1 Test Results Box's M

\begin{tabular}{|c|c|c|}
\hline \multicolumn{3}{|c|}{ Test Results } \\
\hline Box's M & & 216,629 \\
\hline \multirow{4}{*}{$\mathrm{F}$} & Approx. & 2,136 \\
\hline & df1 & 90 \\
\hline & df2 & 33018,811 \\
\hline & Sig. & ,000 \\
\hline ests nul & of ed & ce matric \\
\hline
\end{tabular}

As the significance level of the Box's M statistical test is $=0,000(<0,05)$ therefore $\mathrm{H}_{0}$ is rejected. Thus, the variants of the data group are non-identical/ heterogeneous. On the discriminant analysis stage, stepwise method is therefore used as follows:

Table 2 Motive Item on Discriminant Analysis

Variables Entered/Removed ${ }^{\text {a,b,c,d }}$

\begin{tabular}{|c|c|c|c|c|c|c|c|}
\hline \multirow{3}{*}{ Step } & \multirow{3}{*}{ Entered } & \multicolumn{6}{|c|}{ Min. D Squared } \\
\hline & & \multirow{2}{*}{ Statistic } & \multirow{2}{*}{ Between Groups } & \multicolumn{4}{|c|}{ Exact $\mathrm{F}$} \\
\hline & & & & Statistic & df1 & df2 & Sig. \\
\hline 1 & $\begin{array}{c}\text { Desire to } \\
\text { experience } \\
\text { analog camera }\end{array}$ & ,223 & $\begin{array}{l}\text { Analog Camera } \\
\text { and Digital } \\
\text { Camera }\end{array}$ & 4,044 & 1 & 116,000 &, 047 \\
\hline 2 & $\begin{array}{l}\text { Desire to gain } \\
\text { prestige }\end{array}$ & ,399 & $\begin{array}{c}\text { Analog Camera } \\
\text { and Digital } \\
\text { Camera }\end{array}$ & 3,589 & 2 & 115,000 & ,031 \\
\hline
\end{tabular}

At each step, the variable that maximizes the

Mahalanobis distance between the two closest groups is entered.

a) Maximum number of steps is 18 .

b) Minimum partial $\mathrm{F}$ to enter is 3.84 .

c) Maximum partial $\mathrm{F}$ to remove is 2.71 .

d) F level, tolerance, or VIN insufficient for further computation

The test above shows that there are two stages which result two motives of differentiating the analog camera users and digital camera. They are "desire_to experience_analog" and "desire_to gain_prestige". Both have a significant value of Exact $\mathrm{F}(<0,05)$.

Table 3 Wilks' Lambda andF Value Test

\begin{tabular}{|c|c|c|c|c|c|c|c|c|c|}
\hline \multirow{2}{*}{ Step } & \multirow{2}{*}{$\begin{array}{c}\text { Number of } \\
\text { Variables }\end{array}$} & Lambda & \multirow{2}{*}{ df1 } & \multirow{2}{*}{ df2 } & \multirow{2}{*}{ df3 } & \multicolumn{4}{|c|}{ Exact F } \\
\cline { 7 - 10 } & 1 &, 703 & 1 & 2 & 116 & 24,499 & 2 & 116,000 &, 000 \\
2 & 2 &, 634 & 2 & 2 & 116 & 14,742 & 4 & 230,000 &, 000 \\
\hline
\end{tabular}

The table shows the changing of Lambda value and $\mathrm{F}$ Value Test in each stage. The significance value $<0,05$ reach at second step. Therefore, both motives are all considered in discriminant model. The significance value for the two motives are 0,000: at first step $\mathrm{F}$ value $=$ 24,499 and at the second step $F$ value 14,742. As the 
significancece value is $0,000(<0,05)$ therefore both motives in each category actually have significant difference.

Table 5 The Eigenvalues and Canonical Correlation

\begin{tabular}{|c|c|c|c|c|}
\hline Function & Eigenvalue & $\begin{array}{c}\% \text { of } \\
\text { Variance }\end{array}$ & $\begin{array}{c}\text { Cumulative } \\
\%\end{array}$ & $\begin{array}{c}\text { Canonical } \\
\text { Correlation }\end{array}$ \\
\hline 1 & ${, 575^{a}}^{a}$ & 99,6 & 99,6 &, 604 \\
2 &, $002^{\mathrm{a}}$ &, 4 & 100,0 &, 048 \\
\hline
\end{tabular}

a. First 2 canonical discriminant functions were used in the analysis

As shown above, Function 1 has Eigenvalues $=0,575$ for two motives within that discriminant function. Function 1 may explain the $99,6 \%$ variants in the use of camera. The canonical correlation value shows the relation of discriminant value to the group. The canonical correlation value is 0,604 , which means $36,48 \%$ variants of the independent variable (group) can be explained from the resulted discriminant model. The value 0,604 describes that its correlation is quite high.

Table 6 Wilks' Lambda value for the discriminant function test

\begin{tabular}{|l|c|c|c|c|}
\hline $\begin{array}{c}\text { Test of } \\
\text { Function(s) }\end{array}$ & $\begin{array}{c}\text { Wilks' } \\
\text { Lambda }\end{array}$ & Chi-square & df & Sig. \\
\hline 1 through 2 &, 634 & 52,722 & 4 &, 000 \\
\hline 2 &, 998 &, 271 & 1 &, 602 \\
\hline
\end{tabular}

Based on the Wilks' Lambda table, it is understood if the employed factors are factor 1 up to 2 (both existing factors) then Chi Square value is 52,722 and its significance value is 0,000 . It indicates a significant difference among the three groups of camera users. However, if only 2 factors here, the difference becomes insignificant (Chi Square =0,271 and Sig. <0,05).

Table 7 Standardized Canonical Discriminant Function Coefficients

\begin{tabular}{|l|c|c|}
\hline \multirow{2}{*}{} & \multicolumn{2}{|c|}{ Function } \\
\cline { 2 - 3 } & 1 & 2 \\
\hline $\begin{array}{l}\text { Desire to experience analog } \\
\text { camera }\end{array}$ &, 927 &, 399 \\
\hline Desire to gain prestige &,- 521 &, 865 \\
\hline
\end{tabular}

From the table above, it is known that function 1 is the motive of "desire to get a different experience in using analog camera" with a correlation score $=0,927$, meanwhile function 2 is "desire to gain prestige" with a correlation score $=0,865$.
Table 8 Matrix Structure of Discriminant Function

\begin{tabular}{|c|c|c|}
\hline \multirow[b]{2}{*}{ MOTIVE ITEMS } & \multicolumn{2}{|c|}{ Function } \\
\hline & 1 & 2 \\
\hline Desire to experience analog camera &, $857^{*}$ & 516 \\
\hline Desire to have unique analog images &, $602^{*}$ & 441 \\
\hline Desire to train analog ability ${ }^{b}$ &, $571^{*}$ & 410 \\
\hline Desire to cultivate creativity $^{b}$ &, $551^{*}$ & 421 \\
\hline $\begin{array}{l}\text { Desire to recognize photographer } \\
\text { references }^{b}\end{array}$ &, $364^{*}$ & ,327 \\
\hline Desire to gain prestige &,- 396 & ,918* \\
\hline Desire to cultivate skills ${ }^{\mathrm{b}}$ & ,206 &, $521^{*}$ \\
\hline Desire to add friends & ,148 &, $327^{*}$ \\
\hline Desire to remove boredom ${ }^{b}$ &, 051 &, $291^{*}$ \\
\hline \multicolumn{3}{|c|}{$\begin{array}{l}\text { Pooled within-groups correlations between } \\
\text { discriminating variables and standardized canonical } \\
\text { discriminant functions } \\
\text { Variables ordered by absolute size of correlation within } \\
\text { function. }\end{array}$} \\
\hline \multicolumn{3}{|c|}{$\begin{array}{l}\text { *. Largest absolute correlation between each } \\
\text { variable and any discriminant function }\end{array}$} \\
\hline
\end{tabular}

The coefficient for the discriminant function is presented in the following table.

Table 9. Canonical Discriminant Function Coefficients

\begin{tabular}{|l|c|c|}
\hline \multirow{2}{*}{} & \multicolumn{2}{|c|}{ Function } \\
\cline { 2 - 3 } & 1 & 2 \\
\hline Desire to experience analog & 1,590 &, 685 \\
\hline Desire to gain prestige &,- 500 &, 830 \\
\hline (Constant) & $-4,820$ & $-4,371$ \\
\hline Unstandardized coefficients & \\
\hline
\end{tabular}

On the next table, the discriminant function divides the groups of the camera users based on its factor value.

Table 10. Functions at Group Centroids

\begin{tabular}{|c|c|c|}
\hline \multirow{2}{*}{ Camera Type } & \multicolumn{2}{|c|}{ Function } \\
\cline { 2 - 3 } & 1 & 2 \\
\hline Analog Camera &, 894 &,- 050 \\
\hline Digital Camera &, 273 &, 066 \\
\hline Phone Camera &,- 892 &,- 020 \\
\hline $\begin{array}{l}\text { Unstandardized canonical discriminant functions } \\
\text { evaluated at group means }\end{array}$ \\
\hline
\end{tabular}


The analog camera belongs to factor $1(0,894)$, as well as digital and phone camera. Therefore, the use of analog camera by the phone camera users is predicated more by a motive of "desire to get a different experience in using analog cameras". The difference between phone camera users (having a negative sign -0.892) and analog camera users is at the level of desire: analog camera users have more desires than phone camera users.

Table 11. Classification Results

\begin{tabular}{|c|c|c|c|c|c|c|}
\hline \multicolumn{7}{|c|}{ Classification Results ${ }^{\mathrm{a}, \mathrm{c}}$} \\
\hline & & \multirow[b]{2}{*}{ Camera Type } & \multicolumn{3}{|c|}{ Predicted Group Membership } & \multirow[b]{2}{*}{ Total } \\
\hline & & & $\begin{array}{l}\text { Analog } \\
\text { Cameran }\end{array}$ & $\begin{array}{c}\text { Digital } \\
\text { Camera }\end{array}$ & $\begin{array}{l}\text { Phone } \\
\text { Cannera }\end{array}$ & \\
\hline \multirow[t]{6}{*}{ Origiual } & \multirow[t]{3}{*}{ Count } & Analog Camera & 21 & 12 & 1 & 34 \\
\hline & & Digital Camera & 12 & 22 & 5 & 39 \\
\hline & & Phone Camera & 2 & 19 & 25 & 46 \\
\hline & \multirow{3}{*}{$\%$} & Analog Camera & 61,8 & 35,3 & 2,9 & 100,0 \\
\hline & & Digital Camera & 30,8 & 56,4 & 12,8 & 100,0 \\
\hline & & Phone Canera & 4,3 & 41,3 & 54,3 & 100,0 \\
\hline \multirow{6}{*}{$\begin{array}{l}\text { Cross- } \\
\text { validated }\end{array}$} & \multirow{3}{*}{ Comt } & Analog Camera & 21 & 12 & 1 & 34 \\
\hline & & Digital Camera & 12 & 22 & 5 & 39 \\
\hline & & Phone Camera & 2 & 19 & 25 & 46 \\
\hline & \multirow{3}{*}{$\%$} & Analog Camera & 61,8 & 35,3 & 2,9 & 100,0 \\
\hline & & Digital Camera & 30,8 & 56,4 & 12,8 & 100,0 \\
\hline & & Phone Comera & 4,3 & 41,3 & 54,3 & 100,0 \\
\hline
\end{tabular}

a. $57,1 \%$ of original grouped cases correctly classified.

b. Cross validation is done only for those cases in the analysis. In cross validation, each case is classified by the functions derived from all cases other than that case.

\section{c. $57,1 \%$ of cross-validated grouped cases correctly} classified.

The Original section shows that those who were, in the beginning, the analog camera users (34), from the discriminant model, 21 respondents keep using analog camera $(61,8 \%)$. The digital camera users who keep using the digital camera are $56,4 \%$, and the phone camera users keep using the phone camera are $41,3 \%$. The table above displays the accuracy of this discriminant model up to $57,1 \%$. If it is generally concluded based on the motive, the use of analog camera is predicated by the motives of a desire to experience the analog camera and a desire to gain prestige.

\subsection{Perception}

The highest mean value $(3,82)$ is on the perception of "to have unique analog camera images" among the analog camera users; while within the digital camera users, the highest mean value is 3,63 on the perception "to have different experience". Likewise, within the phone camera users, the highest mean value is on the perception "to have different experience" $(3,19)$. In the following, the test of equality of group means is conducted as follows.
Table 12 Tests of Equality of Group Means

\begin{tabular}{|l|r|r|r|r|r|}
\hline & $\begin{array}{c}\text { Wilks' } \\
\text { Lambda }\end{array}$ & \multicolumn{1}{|c|}{ F } & \multicolumn{1}{|c|}{ df1 } & \multicolumn{1}{c|}{ df2 } & \multicolumn{1}{|c|}{ Sig. } \\
\hline $\begin{array}{l}\text { 1. Perception to have mique analog canera } \\
\text { images }\end{array}$ & 0,925 & 4,688 & 2 & 116 & 0,011 \\
\hline $\begin{array}{l}\text { 2. Perception to merely cultivate photography } \\
\text { skills }\end{array}$ & 0,932 & 4,215 & 2 & 116 & 0,017 \\
\hline 3. Percpetion to have different experience & 0,937 & 3,882 & 2 & 116 & 0,023 \\
\hline $\begin{array}{l}\text { 4. Perception to have photography references on } \\
\text { analog camera }\end{array}$ & 0,939 & 3,765 & 2 & 116 & 0,026 \\
\hline 5. Perception to look prestigious & 0,946 & 3,311 & 2 & 116 & 0,04 \\
\hline 6. Perception to look skillful in photography & 0,95 & 3,057 & 2 & 116 & 0,051 \\
\hline 7. Perception to merely remove boredon & 0,954 & 2,797 & 2 & 116 & 0,065 \\
\hline 8. Perception to look vintage & 0,975 & 1,472 & 2 & 116 & 0,234 \\
\hline 9. Percpetion to look more creative & 0,988 & 0,705 & 2 & 116 & 0,496 \\
\hline 10. Perception to have wider network & 0,991 & 0,528 & 2 & 116 & 0,591 \\
\hline 11. Perception to know the analog system & 0,994 & 0,366 & 2 & 116 & 0,694 \\
\hline $\begin{array}{l}\text { 12. Percpetion to know the superiority and } \\
\text { shortcomings of analog }\end{array}$ & 0,999 & 0,079 & 2 & 116 & 0,924 \\
\hline
\end{tabular}

The Tests of Equality of Group Means table above shows that only five items of perception (no.1 - no. 5) have a significant Wilks' Lambda value at the level $<0.05$. This means that five items show the differences between the groups of the camera type usage. The five items are:

a) Perception to have unique analog camera images

b) Perception to merely cultivate photography skills

c) Percpetion to have different experience

d) Perception to have photography references on analog camera

e) Perception to look prestigious

Researchers employed the Box's 'M test to find out the equality of the variants. The results of the Box's $M$ test are as follows.

Table 13 The Box's 'M Test Results

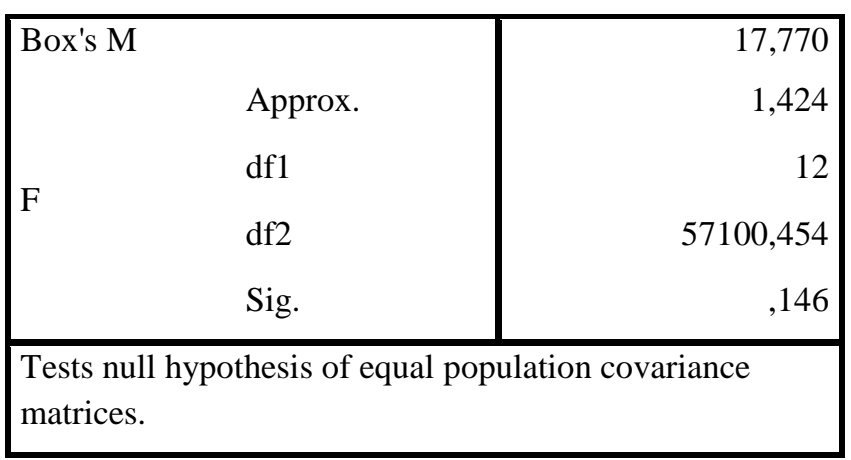

As the Sig, of Box's M statistical test is $=0,146$ ( $>$ $0,05)$ hence $\mathrm{H}_{0}$ is approved. Thus, the variants of the data group are identical or homogeneous. In the discriminant analysis stage, stepwise method is used as follows:

Table 14 Discriminant Analysis

\begin{tabular}{|c|c|c|c|c|c|c|c|}
\hline \multicolumn{8}{|c|}{ Variables Entered/Removed ${ }^{p, b, c, c, d}$} \\
\hline \multirow{3}{*}{ Step } & \multirow{3}{*}{ Entered } & \multicolumn{6}{|c|}{ Min. D Squared } \\
\hline & & \multirow{2}{*}{ Statistic } & \multirow{2}{*}{ Between Gronps } & \multicolumn{4}{|c|}{ Exact F } \\
\hline & & & & Statistic & df1 & df2 & Sig. \\
\hline 1 & $\begin{array}{l}\text { Perception to have } \\
\text { umique amalog camera } \\
\text { images }\end{array}$ & , 104 & $\begin{array}{c}\text { Digital Camera and } \\
\text { Phone Camera }\end{array}$ & 2,203 & 1 & 116,000 & ,140 \\
\hline 2 & $\begin{array}{l}\text { Perception to look } \\
\text { skilful in photography }\end{array}$ & ,318 & $\begin{array}{c}\text { Digital Camera and } \\
\text { Phone Camera }\end{array}$ & 3,325 & 2 & 115,000 & 039 \\
\hline 3 & $\begin{array}{l}\text { Perception to merely } \\
\text { cultivate photography } \\
\text { skills }\end{array}$ & ,319 & $\begin{array}{l}\text { Digital Camera and } \\
\text { Phone Camera }\end{array}$ & 2,205 & 3 & 114,000 & 091 \\
\hline
\end{tabular}




\author{
At each step, the variable that maximizes the Mahalanobis \\ distance between the two closest groups is entered. \\ a. Maximum number of steps is 24 . \\ b. Maximum significance of $\mathrm{F}$ to enter is .05 . \\ c. Minimum significance of $\mathrm{F}$ to remove is .10 . \\ d. F level, tolerance, or VIN insufficient for further \\ computation.
}

From the analysis above, it can be inferred that three stages create three perceptions which distinguish the analog and digital camera users, respectively: (1) Perception to have unique analog camera images. (2) Perception to look skilful in photography. (3) Perception to merely cultivate photography skills.

Table 15 Perception Analysis

\begin{tabular}{|l|c|c|c|c|}
\hline \multicolumn{5}{|c|}{ Variables in the Analysis } \\
\hline \multicolumn{1}{|c|}{ Step } & Tolerance & $\begin{array}{r}\text { Sig. of } \\
\text { F to } \\
\text { Remov } \\
\text { e }\end{array}$ & $\begin{array}{r}\text { Min. D } \\
\text { Squared }\end{array}$ & $\begin{array}{c}\text { Between } \\
\text { Groups }\end{array}$ \\
\hline $\begin{array}{l}\text { Perception } \\
\text { to have } \\
\text { unique } \\
\text { analog } \\
\text { camera } \\
\text { images }\end{array}$ &, 772 &, 000 &, 102 & $\begin{array}{c}\text { Camera } \\
\text { and } \\
\text { Phone }\end{array}$ \\
\hline $\begin{array}{l}\text { Perception } \\
\text { to look } \\
\text { skilful in } \\
\text { photography }\end{array}$ &, 761 &, 037 &, 136 & $\begin{array}{c}\text { Camera } \\
\text { Camera } \\
\text { and }\end{array}$ \\
\hline $\begin{array}{l}\text { Phone } \\
\text { photography } \\
\text { skills }\end{array}$ &, 744 \\
$\begin{array}{l}\text { Perception } \\
\text { to merely } \\
\text { cultivate }\end{array}$ &, 007 &, 318 & $\begin{array}{c}\text { Camera } \\
\text { and } \\
\text { Phone } \\
\text { Camera }\end{array}$ \\
\hline
\end{tabular}

To find out how well each level of independent variables contributed to the model, The Wilks' Lambda test is used. The results of Wilks' Lambda test are as follows:

Table 16. Wilks Lambda

\begin{tabular}{|c|c|r|r|r|r|r|r|r|r|}
\hline \multicolumn{10}{|c|}{ Wilks' Lambda } \\
\hline Step & $\begin{array}{c}\text { Number of } \\
\text { Variables }\end{array}$ & Lambda & df1 & df2 & df3 & \multicolumn{5}{|c|}{ Exact F } \\
\cline { 7 - 12 } & 1 &, 925 & 1 & 2 & 116 & 4,688 & 2 & 116,000 &, 011 \\
\hline 1 & 1 &, 821 & 2 & 2 & 116 & 5,952 & 4 & 230,000 &, 000 \\
\hline 3 & 3 &, 752 & 3 & 2 & 116 & 5,827 & 6 & 228,000 &, 000 \\
\hline
\end{tabular}

The table shows the changing of Wilks' Lambda value and $\mathrm{F}$ Value Test in each stage. The significance value < 0,05 reach at third step. Therefore, the three perceptions are all considered in discriminant model. The significance value for the three perceptions are: on step $1, \mathrm{~F}$ value = 4,688 with Sig. $=0,011$; on step $2, \mathrm{~F}$ value $=5,952$ with Sig. = 0,000; on step 3, F value of 5,827 with Sig. $=0,000$. As the significance value is $0,000(<0,05)$ therefore all perceptions in each category actually have significant difference.

Table 17. Eigenvalues

\begin{tabular}{|c|c|c|c|c|}
\hline Function & Eigenvalue & $\begin{array}{c}\% \text { of } \\
\text { Variance }\end{array}$ & $\begin{array}{c}\text { Cumulative } \\
\%\end{array}$ & $\begin{array}{c}\text { Canonical } \\
\text { Correlation }\end{array}$ \\
\hline 1 &, $307 \mathrm{a}$ & 94,6 & 94,6 &, 485 \\
\hline 2 &, $018 \mathrm{a}$ & 5,4 & 100,0 &, 131 \\
\hline
\end{tabular}

First 2 canonical discriminant functions were used in the analysis.

As shown above, Function 1 has Eigenvalues $=0,307$ for three perception within that discriminant function. Function 1 may explain the 94,6\% variants in the use of camera. The canonical correlation value shows the relation of discriminant value to the group. The canonical correlation value is 0,485 , which means $23,85 \%$ variants of the independent variable (group) can be explained from the resulted discriminant model. The value 0,485 describes that its correlation is rather low.

Table 18. Wilks' Lambda

\begin{tabular}{|ccccc|}
\hline $\begin{array}{c}\text { Test of } \\
\text { Function(s) }\end{array}$ & $\begin{array}{c}\text { Wilks' } \\
\text { Lambda }\end{array}$ & $\begin{array}{c}\text { Chi- } \\
\text { square }\end{array}$ & Df & Sig. \\
\hline 1 through 2 &, 752 & 32,812 & 6 &, 000 \\
2 &, 983 & 2,002 & 2 &, 367 \\
\hline
\end{tabular}

Based on the Wilks' Lambda table above, it can be recognized that the factors used here were factor 1 up to 2 (or both existing factors) therefore Chi Square value is 32,812 and significant at 0,000 . This thereby indicates a significant difference among the three groups of camera users. However, if only 2 factors were used, the difference becomes insignificant (Chi Square $=2,002$ and significance $>0,05)$

As carefully observed below, factor 1 describes the "perception to have unique analog camera images". Meanwhile, factor 2 is "perception to merely cultivate photography skills" and "perception to look skilful in photography". 
Table 19. Standardized Canonical Discriminant Function Coefficients

\begin{tabular}{|lcc|}
\hline & \multicolumn{2}{c|}{ Function } \\
\cline { 2 - 3 } & 1 & 2 \\
\hline $\begin{array}{l}\text { a) Perception to have unique analog } \\
\text { camera images }\end{array}$ &,- 977 &, 194 \\
$\begin{array}{l}\text { b) Perception to merely cultivate } \\
\text { photography skills }\end{array}$ &, 645 &, 959 \\
$\begin{array}{l}\text { c) Perception to look skilful in } \\
\text { photography }\end{array}$ &, 511 &,- 841 \\
\hline
\end{tabular}

These results were less consistent with the Matrix Structure below.

Table 20. Structure Matrix

\begin{tabular}{|lcc|}
\hline & \multicolumn{2}{c|}{ Function } \\
\cline { 2 - 3 } & 1 & 2 \\
\hline $\begin{array}{l}\text { a) Perception to have unique analog } \\
\text { camera images }\end{array}$ &,$- 509^{*}$ &, 263 \\
b) Perception to look skilful in & & \\
photography &, $405^{*}$ &,- 354 \\
c) Perception to have different experience &,$- 304^{*}$ &, 068 \\
d) Perception to remove boredom & \\
e) Perception to gain prestige &, $296^{*}$ &,- 014 \\
f) Perception to look more creative &, $293^{\text {b }}$ &,- 084 \\
g) Perception to look vintage &, $246^{*}$ &,- 109 \\
h) Perception to have wider network &, $192^{*}$ &, 050 \\
i) Perception to merely cultivate &, $101^{*}$ &,- 016 \\
$\begin{array}{l}\text { photography skills } \\
\text { j) Perception to now the system of analog }\end{array}$ &,- 077 &, $235^{*}$ \\
k) Perception to know the superiority and &,- 117 &, $200^{*}$ \\
$\begin{array}{l}\text { shortcomings of analog } \\
\text { l) Perception to have photography of }\end{array}$ &,- 112 &, $158^{*}$ \\
analog camera images & & \\
\hline
\end{tabular}

Pooled within-groups correlations between discriminating variables and standardized canonical discriminant functions

Variables ordered by absolute size of correlation within function.

*. Largest absolute correlation between each variable and any discriminant function. This variable not used in the analysis.

Based on the structure matrix table, factor 1 consists of: "perception to have unique analog camera images" and "perception to look skilful in photography". Meanwhile factor 2 consists "perception to merely cultivate photography skills", as within that factor it has the largest absolute correlation between each variable and any discriminant function.

Function in Group Centroids can be interpreted as follows: (1) In the analog camera users group, the factor is 1 , it is "to have a unique analog camera images" and "to look skilful in photography". (2) Also, in the phone camera users, the factor is 1 , it is "to have to have a unique analog camera images" and "to look skilful in photography". (3) Meanwhile, in the digital camera users, the factor is 2 , it is "to merely cultivate the photography skills".

Table 21. Functions at Group Centroids

\begin{tabular}{|l|r|r|}
\hline \multirow{2}{*}{ Camera type } & \multicolumn{2}{|c|}{ Function } \\
\cline { 2 - 3 } & 1 & \multicolumn{1}{|c|}{2} \\
\hline Analog Camera &,- 803 &,- 077 \\
\hline Digital Camera &, 058 &, 187 \\
\hline Phone Camera &, 544 &,- 101 \\
\hline
\end{tabular}

Unstandardized canonical discriminant functions evaluated at group means

However, glared at the negative sign on $-0,803$ score on analog camera, this thing can therefore be interpreted that the perception of respondents of analog camera users is not too "perceive the typical work of analog cameras" and "not look too skilful in photography." In contrast, respondents of phone camera users perceive "the work of analog cameras is unique and looks skillfull in photography". This can also be seen in the figure below.

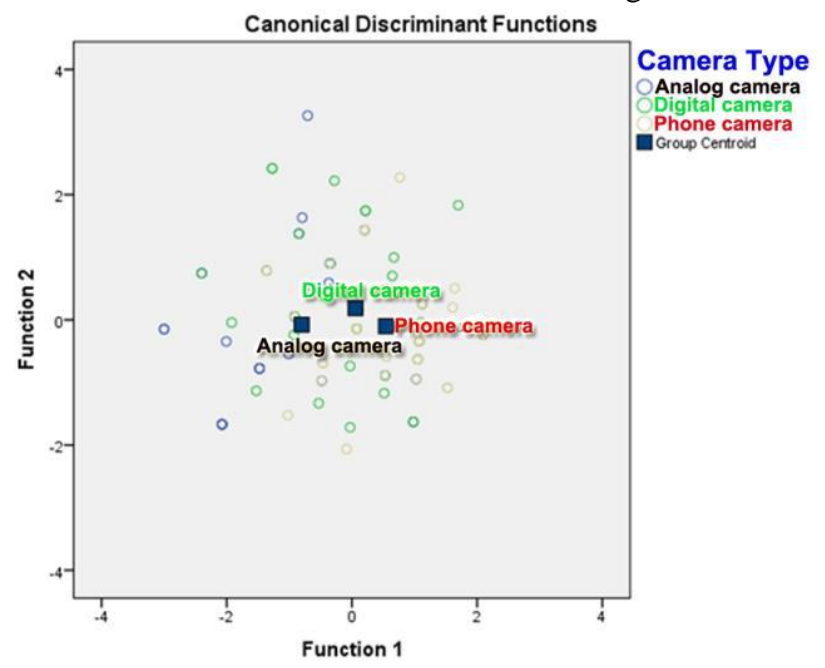

Fig.1: Graph of Individuals on The Discriminant Dimensions

The prediction of discriminant model reaches $47,1 \%$, as seen on the cross-validated grouped cases correctly 
classified in the following table.

Table 22. Classification Results

\begin{tabular}{|c|c|c|c|c|c|c|}
\hline \multicolumn{7}{|c|}{ Classification Results ${ }^{\mathrm{a}, \mathrm{c}}$} \\
\hline & & \multirow[b]{2}{*}{ Camera Type } & \multicolumn{3}{|c|}{ Predicted Group Membership } & \multirow[b]{2}{*}{ Total } \\
\hline & & & $\begin{array}{c}\text { Analog } \\
\text { Camera }\end{array}$ & $\begin{array}{c}\text { Digital } \\
\text { Camera }\end{array}$ & $\begin{array}{c}\text { Phone } \\
\text { Camera }\end{array}$ & \\
\hline \multirow{6}{*}{ Original } & \multirow{3}{*}{ Count } & Analog Camera & 18 & 10 & 6 & 34 \\
\hline & & Digital Camera & 10 & 15 & 14 & 39 \\
\hline & & Phone Camera & 7 & 12 & 27 & 46 \\
\hline & \multirow{3}{*}{$\%$} & Analog Camera & 52,9 & 29,4 & 17,6 & 100,0 \\
\hline & & Digital Camera & 25,6 & 38,5 & 35,9 & 100,0 \\
\hline & & Phone Camera & 15,2 & 26,1 & 58,7 & 100,0 \\
\hline \multirow{6}{*}{$\begin{array}{l}\text { Cross- } \\
\text { validated }^{b}\end{array}$} & \multirow{3}{*}{ Count } & Analog Camera & 17 & 11 & 6 & 34 \\
\hline & & Digital Camera & 11 & 14 & 14 & 39 \\
\hline & & Phone Camera & 8 & 13 & 25 & 46 \\
\hline & \multirow{3}{*}{$\%$} & Analog Camera & $\mathbf{5 0 , 0}$ & 32,4 & 17,6 & 100,0 \\
\hline & & Digital Camera & 28,2 & 35,9 & 35,9 & 100,0 \\
\hline & & Phone Camera & 17,4 & 28,3 & 54,3 & 100,0 \\
\hline
\end{tabular}

a. $50,4 \%$ of original grouped cases correctly classified.

b. Cross validation is done only for those cases in the analysis. In cross validation, each case is classified by the functions derived from all cases other than that case.

c. $47,1 \%$ of cross-validated grouped cases correctly classified.

Generally, it can be concluded that on the matter of perception, the use of analog camera is predicated on "perception to have unique analog camera images" and "perception to look skilful in photography" and "perception to merely cultivate photography skills". The accuracy of the prediction achieves $47,1 \%$.

\subsection{Discussion}

Theoretically, the phenomenon of analog camera usage can be viewed from the Uses and Gratification Theory. This theory suggests the problem of motive behind an action, on the other hand it is hope, which later stems to be perception. Therefore, the use of the dependent variables is predicated on motive and perception.

With the discriminant analysis, the camera (analog, digital, or phone camera) users are classified based on the motive and perception, as there might be a mingling of the participants' exclusive characteristics which may allow the ambiguity of the factors which predicate the reason they use analog camera. The result of discriminant analysis shows those differences. From the motive perspective, the motives of "desire to experience analog camera" and "to gain prestige" distinguish the analog, digital, and phone camera users. The difference, however, is on the negative sign in the phone camera users.
Meanwhile from the perception side, factors "to have unique analog camera images" and "to look skilful in photography" are distinguishing the groups of those using analog camera and phone camera from the digital camera users. However, the analog camera users have more negative perception to those factors compared to phone camera users. Meanwhile, the factor of cultivating photography skills has become a distinguishing factor of the digital camera users group from the other two groups. To explain further, the accuracy of prediction from the discriminant model has actually achieved an average level (in perception), and rather enough in motive

\section{CONCLUSION}

The findings in this research suggest that there is a motive of desire to experience using analog camera and desire to gain prestiges in using analog camera. The accuracy of discriminant model achieves $57.1 \%$. Meanwhile, from the perception view, the use of analog camera is predicated by "the perception to have unique analog camera images", "the perception to look skilful in photography" and "the perception to cultivate photography skills". The accuracy of the prediction reaches $47.1 \%$.

However, it can be thereby concluded that in relation to the Uses and Gratification Theory, the use of media (camera) has correlation with motive and perception.

The recommendation from this research is that to increase the prediction of motive and perception as the distinguishing factors in using media, the future research may consider discovering other aspects, such as hope and other characteristics which are highly linked to the development of technology in this digital era.

\section{ACKNOWLEDGEMENTS}

The authors would like special thanks to Universitas Mercu Buana for give funding for this research.

\section{REFERENCES}

[1] E. M. Rogers, A. Singhal, and M. M. Quinlan, "Diffusion of innovations," in An Integrated Approach to Communication Theory and Research, Third Edition, 2019.

[2] E. M. Rogers, "Evolution: Diffusion of Innovations," in International Encyclopedia of the Social \& Behavioral Sciences: Second Edition, 2015.

[3] E. M. Rogers, Diffusion of Innovations, Fifth Edition. 2003.

[4] A. Malik, A. Dhir, and M. Nieminen, "Uses and Gratifications of digital photo sharing on Facebook," Telemat. Informatics, 2016. 
[5] A. D. Smock, N. B. Ellison, C. Lampe, and D. Y. Wohn, "Facebook as a toolkit: A uses and gratification approach to unbundling feature use," Comput. Human Behav., 2011.

[6] K. C. Schrøder, "News Media Old and New," Journal. Stud., 2015.

[7] D. H. Shin, "Understanding e-book users: Uses and gratification expectancy model," New Media Soc., 2011.

[8] C. Gan, "Understanding WeChat users' liking behavior: An empirical study in China," Comput. Human Behav., 2017.

[9] M. Mondi, P. Woods, and A. Rafi, "A 'Uses and Gratification Expectancy Model' to predict students' 'Perceived e-Learning Experience," Educ. Technol. Soc., 2008.

[10] M. C. Chou and C. H. Liu, "Mobile Instant Messengers and Middle-Aged and Elderly Adults in Taiwan: Uses and Gratifications," Int. J. Hum. Comput. Interact., 2016.

[11] A. Y. K. Chua, D. H. L. Goh, and C. S. Lee, "Mobile content contribution and retrieval: An exploratory study using the uses and gratifications paradigm," Inf. Process. Manag., 2012 .

[12] C. P. Chen, "Understanding mobile English-learning gaming adopters in the self-learning market: The Uses and Gratification Expectancy Model," Comput. Educ., 2018.

[13] T. Huang, Z. Bao, and Y. Li, "Why do players purchase in mobile social network games? An examination of customer engagement and of uses and gratifications theory," Program, 2017.

[14] E. Katz, J. G. Blumler, and M. Gurevitch, "Uses and Gratifications Research,” Public Opin. Q., 1973.

[15] C. Cherniss, C. Roche, and B. Barbarasch, "Emotional Intelligence," in Encyclopedia of Mental Health: Second Edition, 2016.

[16] Beely Jovan Sumakul, "PERANAN KOMUNIKASI KELUARGA DALAM PEMBENTUKAN IDENTITAS REMAJA DI KELURAHAN MALALAYANG I KECAMATAN MALALAYANG KOTA MANADO," $e$ journal “Acta Diurna," 2016.

[17] D. McQuail, Mass Communication. 2014.

[18] J. D. H. Downing, D. McQuail, P. Schlesinger, and E. A. Wartella, The SAGE handbook of media studies. 2004.

[19] D. McQuail, "Mass Communication," in The International Encyclopedia of Political Communication, 2016.

[20] A. Ignatov, N. Kobyshev, R. Timofte, K. Vanhoey, and L. Van Gool, "DSLR-Quality Photos on Mobile Devices with Deep Convolutional Networks," in Proceedings of the IEEE International Conference on Computer Vision, 2017.

[21] T. Schöps et al., "A multi-view stereo benchmark with highresolution images and multi-camera videos," in Proceedings - 30th IEEE Conference on Computer Vision and Pattern Recognition, CVPR 2017, 2017.

[22] P. Pusparani and N. Rastini, "PENGARUH KUALITAS
PRODUK DAN BRAND IMAGE TERHADAP KEPUASAN KONSUMEN DAN LOYALITAS PELANGGAN KAMERA CANON DIGITAL SINGLE LENS REFLEX (DSLR) DI KOTA DENPASAR," E-Jurnal Manaj. Univ. Udayana, 2014.

[23] Y. Wang, Y. Liu, W. Heidrich, and Q. Dai, "The Light Field Attachment: Turning a DSLR into a Light Field Camera Using a Low Budget Camera Ring," IEEE Trans. Vis. Comput. Graph., 2017.

[24] M. Zhang et al., "Precision multiband photometry with a DSLR camera," Publ. Astron. Soc. Pacific, 2016.

[25] F. Williams and P. R. Monge, "Reasoning With Statistics: How To Read Quantitative Research," Aust. Thomson Wadsworth, 2001.

https://tekno.kompas.com/read/2016/09/13/10470087/ap a.itu.kamera.mirrorless.bedanya.den gan.dslr. Accessed in March 27, 2018

[26] https://tekno.kompas.com/read/2017/08/05/10465657/berken alan-dengan-kamera-film-yang- kembali-digandrungi-diindonesia?page+all. Accessed in April 13, 2018

[27] https://www.antaranews.com/berita/658414/kamera-analogkembali-dicari-kenapa. Accessed in March, 272018

[28] https://tekno.kompas.com/read/2017/08/02/14282837/kamer a-roll-film-ngetren-lagi-foto- $35 \mathrm{~mm}$-ramai-di-instagramtanah-air. Accessed in March, 27 of 2018

[29] http://scdc.binus.ac.id/klifonara/2017/06/kelebihan-kameraanalog/. Accessed in March 27, 2018

[30] https://daily.oktagon.co.id/kelas-pagi-kelas-fotografi-untuksemua/. Accessed in August 4, 2018 